\title{
An isocratic normal-phase high-performance liquid chromatographic method for the simultaneous determination of benzoyl peroxide and benzoic acid in one pharmaceutical preparation and their stability in different solvents
}

\author{
Hazim Hamid Hamdu \\ (Department of pharmaceutical chemistry and pharmacognacy, Baghdad College of pharmacy/ syndicate of Iraqi \\ pharmacists, Iraq)
}

\begin{abstract}
A normal-phase high-performance liquid chromatographic method was developed for the simultaneous determination of benzoyl peroxide (BPO) and benzoic acid (BA). The compounds are separated on a normal phase column Eurospher-100, c18.4.6mmID. The mobile phase is methanol - water $(65+35, v / v)$. Solutions are injected into the chromatographic system under isocratic conditions at a constant flow rate of 1 $\mathrm{mL} / \mathrm{min}$ with $U V$ detection at $240 \mathrm{~nm}$. Analysis of stability samples in deferent solvents showed formation of $B P O$ from BA when it dissolved in ether or methanol and very low degradation of BPO to BA when it dissolved in ether compare with when it dissolved in methanol
\end{abstract}

Keywords: benzoic acid, benzoyl peroxide, HPLC, normal phase, solvents

\section{Introduction}

A. Benzoyl peroxide [BPO] is an organic compound in the peroxide family. It consists of two benzoyl groups bridged by a peroxide link. Its structural formula is $\left[\mathrm{C}_{6} \mathrm{H}_{5} \mathrm{C}(\mathrm{O})\right]_{2} \mathrm{O}_{2}$. It is one of the most important organic peroxides in terms of applications and the scale of its production. Benzoyl peroxide is used as an acne treatment, for improving flour, for bleaching hair and teeth, for polymerizing polyester and many other uses. Benzoyl peroxide is included in the World Health Organization (WHO) Model Lists of Essential medicines, which is a list of minimum medical needs for a basic health care system<smiles>O=C(OOC(=O)c1ccccc1)c1ccccc1</smiles>

Benzoyl peroxide [BPO]

Benzoyl peroxide was the first organic peroxide prepared by intentional synthesis. It was prepared by treating benzoyl chloride with barium peroxide, [1] a reaction that probably follows this equation:

\section{II. $\quad \mathrm{C}_{6} \mathrm{H}_{5} \mathrm{C}(\mathrm{O}) \mathrm{Cl}+\mathrm{BaO}_{2} \rightarrow\left[\mathrm{C}_{6} \mathrm{H}_{5} \mathrm{C}(\mathrm{O})\right]_{2} \mathrm{O}_{2}+\mathrm{BaCl}_{2}$------ Equation 1}

Benzoyl peroxide is usually prepared by treatinghydrogen peroxide with benzoyl chloride. The oxygenoxygen bond in peroxides is weak. Thus benzoyl peroxide readily undergoes homolysis (symmetrical fission), forming free radicals:

$\left[\mathrm{C}_{6} \mathrm{H}_{5} \mathrm{C}(\mathrm{O})\right]_{202} \rightarrow 2 \mathrm{C}_{6} \mathrm{H}_{5} \mathrm{CO}_{2}$

Equation 2

The symbol ${ }^{\circ}$ indicates that the products are radicals; i.e., they contain at least one unpaired electron. Such species are highly reactive. The hemolysis is usually induced by heating. The half-life of benzoyl peroxide is one hour at $92{ }^{\circ} \mathrm{C}$. At $131{ }^{\circ} \mathrm{C}$, the half-life is one minute. [2] Benzoyl peroxide breaks down in contact with skin, producing benzoic acid and oxygen, neither of which is significantly toxic.[3] It is important to note that the safety of the decomposition products does not mean that the substance itself is safe, as it is benzoyl peroxide's action as an oxidizing agent that is of importance. Hydrogen peroxide can be corrosive due to its oxidizing properties, but decomposes to form water and oxygen. Sodium hypochlorite (commonly known as "bleach") also shares these properties, but disproportion rates to form harmless products such as sodium chloride most benzoyl peroxide is used as a radical initiator to induce polymerizations. [4] Other major applications include its antiseptic and bleaching properties. Benzoyl peroxide for acne treatment is typically applied to the affected areas in gel or cream form, in concentrations of $2.5 \%$ increasing through $5 \%$, and up to $10 \%$. Research suggests that $5 \%$ and $10 \%$ concentrations are not significantly more effective than $2.5 \%$, while $2.5 \%$ is usually better tolerated .Benzoyl peroxide is an oxidizing agent. The methods of analysis either make use of its oxidizing properties or the benzoyl peroxide is reduced to benzoic acid, which is then assayed. 
(1) Reduction to benzoic acid-an ethereal suspension of the food sample reduced with iron/aqueous hydrochloric acid. The benzoic acid formed is estimated. ${ }^{[5]}$

(2) Titrimetric method - an aqueous solution of potassium iodide is added to the acetone extract containing the benzoyl peroxide. The liberated iodine is immediately titrated against standard thiosulphate. ${ }^{[6]}$

(3) Color test-If benzoyl peroxide is present in flour, a blue-green color is produced when a few drops of one per cent alcoholic 4, 4'-diaminodiphenylaminesolution are added. ${ }^{[7]}$

(4) Polar graphic method - is a specific and very sensitive method for benzoyl peroxide. ${ }^{[8]}$

(5) Other methods - Leucomethylene blue method. Benzoyl peroxide can be estimated by using it to oxidize leucomethylene blue to the intensely colored methylene blue. ${ }^{[9]}$

(6) Identification by high-performance liquid chromatography-mass spectrometry.

Benzoic acid [BA]<smiles>O=C(O)c1ccccc1</smiles>

Benzoic acid is carboxylic acid, it is present naturally either free or bounds benzoic acid esters and can be found in many natural products [10].Benzoic acid is extensively used as preserving agent most suitable for foods, fruit juices, and soft drinks. It is harmful at higher than permitted safety levels [11].In humans, the acute toxicity of benzoic acid is low symptoms appear shortly after exposure and disappear within a fewhours, even at low doses [12].Analytical methods for the determination of benzoic acid include spectrophotometric methods [13], which need extensive extraction procedures and are not very specific; gas chromatographic (GC) methods [14], which are more sensitive and specific but need lengthy sample preparation and derivatization prior to determination using high-performance liquid chromatography(HPLC)[15], which has a high specificity and minimum sample preparation and does not require derivatization. Other methods were used to assay benzoic acid like GC-MAS [16] and GC with on line pyrolytic methylation technique [17].

\section{Benzoyl peroxide [BPO] and Benzoic acid [BA] combination assay}

Spectrophotometric method was used to determine Benzoyl peroxide and Benzoic acid combination [18]. Only one HPLC-UV method [19] for the simultaneous determination of benzoyl peroxide and the related compounds benzoic acid was done in [2008]. Different new HPLC-UV with instrument set-up we do in this research.

\section{Instrument and Apparatus}

- $\quad$ Specord 40 ( analytike Jena) (USA)

- HPLC (Thermo, USA) which consist of:

- Gradient isocratic pumpfinniganspectraSystem P2000.

- Degasser spectraSystemSGM 1000.

- UV detector spectraSystem UV1000.

- $250 \times 4.6 \mathrm{~mm}$ Hyperclone 5u ODS (C18) 120 A phenomenex column. (USA).

- Eurospher-100, c18.4.6mmID KNAUER(Germany).

- Eurospher-100, c18.4.6mmID KNAUER(Germany).

- $\quad$ Eurospher-100, c18Si.4.6mmID KNAUER(Germany).

3- Hot plate with stirrer Raypa AG-C (Korea).

4- Stirring bar - Plastic-coated, magnetic, 1" long.

5-Filler device to produce water for HPLC (Whatman - England)

6-electronic Balance.(Srtorius -USA).

7-altrasonc bath (Power Sonic 410.Humenal lab Korea)

\section{Reagents and materials}

1. Methanol (HPLC grade) scharlab S.L made in Spain

2- Acetontrile (HPLC grade) Gradient $240 \mathrm{~mm}$ for UV scharlab S.L made in Spain

3-Water for HPLC by filter device

4-Benzoyl peroxide anhydrous .Fluka AG, Chemische fabric $\mathrm{CH}$.

5-Benzoic acid. Gerhard Buchmann(Germany).

6-Tetrahydro furan (HPLC grade)Biosolvechimiefrance.

7-Potassium hydrogen phosphate. THOMAS BAKER (INDIA).

8-penoxid acne lotion. (Dominpharma.com .Syria). 
9-N-Hexane. GCC company ,UK.

10. Acetone. THOMAS BAKER (INDIA).

11. Ether. . GCC company ,UK.

12. Sodium thiosulphate anhydrous, A.R(HiMedia laboratories India).

13. Potassium Iodide. EDUTIC chemicals India.

\section{Method}

20UL of test and stander solutions was injected in HPLC-UV detector (Thermo spectra system) with isocratic gradient pump. At UV lambda max (Lmax) 240nm. The rate flow of mobil phase $1 \mathrm{ml} / \mathrm{min}$. using normal phase column (Eruspher - $100 \mathrm{C} 12$. Si, 4.6mm ID) the mobile phase was Methanol; water (65:35) the experiment was carried at room temp.

\section{Preparation of stander solution}

Mixture of 100mg BA and 100mg BPO was dissolved in $100 \mathrm{ml}$ of ether in volumetric flask.

\section{Preparation of test solution.}

We must used in preparation of test solution a pharmaceuticalpreparation contain both BA and BPO so to do this we used expired lotion (Ben - oxide acne lotion) which is expired since august/2010 with stirring for 30 mint we mixed $2 \mathrm{~g}$ of lotion (5g BPO/ $100 \mathrm{~g}$ base) i.e. $100 \mathrm{mg}$ BPO using magnetic stirrer with $60 \mathrm{ml}$ ether in stepper flask. Filter wash the flask and filter paper with ether, add to the filtrate, complete volume to $100 \mathrm{ml}$ of ether in volumetric flask.

\section{Result and calculation}

The HPLC diagrams for stander (Fig-1) and test (Fig-2) shows the fallowing results. Retention time $1.91 \mathrm{mint}$ and $1.908 \mathrm{mint}$ for stander and test BA.And area under the carve 10705049 for stander and 10271877 for the test of BA respectively.While BPO shows retention time 3.20 mints for stander and 3.22mints for test and areaunder carve of 23643851 for stander and 1959850 for the test respectively.

\section{Calculation:-}

To calculate the \% percent of BPO and BA by HPLC we use this equation;

At / As $\mathrm{x}$ weight of stander $=$ weight $(\mathrm{wt})$ of tested material.

$\mathrm{At}=$ area under carve for test material.

As=area under carve for stander.

wt. =weight.

Wt.of test material/wt.of sample x $100=$ tested material $\%$

In our experiment the wt.ofcalculated material willbe equal to its percent (\%).Because the wt. of stander $=100 \mathrm{mg}$.So it will conceal the 100 of the percent. The wt. of BA in our test sample byour HPLC method $=95.5 \mathrm{mg}$ and For $\mathrm{BPO}=6.00 \mathrm{mg}$

Total wt of test $=95.9 \mathrm{mg}+6.00 \mathrm{mg}=101.9 \mathrm{mg}$.

$=101.9 \%$ which comply with USP which indicate that acne lotion contained not more than $110 \%$ not less than $90 \%[20]$.

\section{Accuracy and Validity.}

To check the accuracy of our HPLC assay. We have to do different method of assay to our acne lotion for BA and BPO. Acid-base analysis for BA and iodometric analysis for BPO.was done in order to correlateboth results.

VI.1- assay of BA by acid base titration we toke $25 \mathrm{ml}$ of our test solution in conical flask add $25 \mathrm{ml}$ of distilled waterand 5 drops of methyl red solution as indicator. And titrate against $0.5 \mathrm{~N} \mathrm{NaOH}$. Each ml of $0.5 \mathrm{~N} \mathrm{NaOH}$ equivalent to $6.1 \mathrm{mg}$ of BA.

VI.2- assay of BPO by Iodometric method.Dissolved $2 \mathrm{mg}$ of test lotion (contain $100 \mathrm{mg}$ ) BPO in $50 \mathrm{ml}$ acetone, complete the volume to $100 \mathrm{ml}$ with acetone.To $20 \mathrm{ml}$ we add $25 \mathrm{ml}$ of $20 \%$ w/v KI and allow standing for 15 minutes protected from light. Add another $10 \mathrm{ml}$ of acetone and titrate with $0.01 \mathrm{M}$ sodium thiosulfate without starch indecator.Each1 $\mathrm{ml}$ of $0.01 \mathrm{M}$ sodium thiosulfate equivalent to $1.211 \mathrm{mg}$ of BPO.

VI.3Result .Volume of $0.5 \mathrm{~N} \mathrm{NaOH}$ needed for $25 \mathrm{ml}$ test solution $\mathrm{BA}=3.9 \mathrm{ml}$.And $1 \mathrm{ml}$ of $0.01 \mathrm{~N}$ sodium thiosulphate we need to react with $20 \mathrm{ml}$ of test solution BPO. 


\section{VI.4-Calculation}

- $\quad 3.9 \times 4 \times 6.1=95.16 \mathrm{mg} \mathrm{BA}$

- $\quad 1 \times 5 \times 1.211=6.03 \mathrm{mg}$ of BPO

Total wt $\%$ of tested material $=95.16+6.03=101.2 \%$

Both methods comply with USP. Comparing with $101.9 \%$ of the HPLC method with small deference between them is only $0.7 \%$.

\section{Chromatographic system- set - up}

Many parameters for HPLC must be setup since both BA and BPO to be assay together.

\section{VII-1. Lambda max (Lmax)}

Experiment -1

Solutions of $50 \mathrm{mg}$ BPO in $100 \mathrm{ml}$ ether and $50 \mathrm{mg}$ BA in $100 \mathrm{ml}$ ether was Scand in specord 40 (UVVisibleapparatus)using ether as blank and absorption scan mode from $190-400[\mathrm{~nm}]$ the delta lambda[nm] $=2$ and speed $[\mathrm{nm} / \mathrm{s}]=50$ the absorbance diagram show in (fig-3) for BPO and (fig-4) for BA. Both show Lmax of $240[\mathrm{~nm}]$.

Experiment -2

To see the exact Lmax of BPO we inject20ul ofBPO $(50 \mathrm{mg} / 100 \mathrm{ml}$ ether) solution in our chromatographic system using mobil phase methanol ; water (80;20).and phenomenex ODS (C18)Column. with rate of flow $1 \mathrm{ml} / \mathrm{mint}$ at room temperature. Werepeated this procedure several time each time with deferent Lmax from $270 \mathrm{~nm}$ to $230 \mathrm{~nm}$. (table-1) shows the result of our experiment and the peak of high resolution was at Lmax 240nm. (Fig-5) the HPLC diagram of BPO at Lmax 240nm.

\section{VII-2. Column}

Two main groups of column are mainly used in chromatography the reversed phase column. and normal phase column to see which type of column is better in separation of AB and BPO mixture with polar mobil phase (methanol 100\%).we do experiment with simple procedure; Our HPLC system was rune two times one with reversed phase column [Hyper clone 5u ODS (C18) $250 * 4.8 \mathrm{~mm} 5$ micron] and anther time with normal phase silica column [Eurospher - $100 \mathrm{C} 18,4.6 \mathrm{~mm} \mathrm{ID]} \mathrm{.At} \mathrm{Lmax} \mathrm{240nm,} \mathrm{rate} \mathrm{of} \mathrm{flow} 1 \mathrm{ml} / \mathrm{mint}$. At room temperature.20ul of BA and BPO $50 \mathrm{mg} / 100 \mathrm{ml}$ ether injected each time in chromatographic system .HPLC diagrams shows that the better separation was in normal phase column (fig-6) than the reversed phase column,(fig-7). Another experiment was done using two deferent normal phase column tosee the best separation we repeated the last experiment one with Eurospher - $100 \mathrm{C} 18.4 .6 \mathrm{~mm}$ ID column and the another with Eurospher - $100 \mathrm{C} 18 \mathrm{si} 1.6 \mathrm{~mm}$ ID column.HPLC diagrams shows a best separation was done when we used C18 -Si column.[ fig -8 ] shows agood separation between BA and BPO compare with ODS column [ fig-7]

\section{VII-3. Mobil phase}

One of the important parameter in HPLC is the mobil phase which play important role in separation and resolution of peaks in HPLC diagrams to choose a good mobil phase for our new method a series of deferent (methanol ;water)mixture as a deferent mobil phase and each one was use in our chromatographic system which set-up with normal phase column .A high resolution diagram for $5 \mathrm{omg} / 100 \mathrm{ml}$ ether of BA and BPO mixture was gained at a mobil phase consists of methanol $65 \%$ and water $35 \%$ as we see in (fig -1) also (fig -8) shows HPLC diagram when $100 \%$ methanol is the mobil phase.

\section{VIII.Effect of Solvents on stabilityof BA and BPO.}

Different researches discussed stability of BPO [19], [21] in ether, ethanol, heat and pharmaceutical preparation. All agreed that BPObecause BPO is an oxidizing agent it will rapidly dissociated to BA. (equation2) mainly by radical mechanism.(Bollinger and Lewis)[21] said that BPO destroy rapidly with one month at3040C andit is more stable in ether than in alcohol. We don't know very much about the stability of BA in deferent solvent. It is very important to study the stability of BA and BPO in the solvent we used in new method. Because it is very important in the validity of method and how much time it takes to does the assay before our tested material start to destroy. To do this study we prepare five different solutions as follow;

- Solution [1] - 250mg/100ml BA in ether.

- Solution [2] - 250mg/100ml BPO in ether.

- Solution [3] - 250mg/100ml BA in methanol.

- Solution [4] - 250mg/100ml BPO in methanol.

- Solution [5] - 250mg/100ml BA in n-Hexane.

These solutions were injected in our HPLC-UV apparatus in different time interval from one hour to 3-4 months. The result of this experiment was plotted in table as follow; (table-2) results for solution [1], ; (table-3) 
results for solution [3], ; (table-4) results for solution [2] and; (table-5) results for solution [4].From these four tables we can say that;

VIII.1. BA in ether and methanol under goes slow reaction time to produced BPO. This is same what faster in ether than in methanol. (Fig-9) HPLC diagram for solution [1] after 1 day storage. (Fig-10) HPLC diagram for solution [1] after 4 months storage.

VIII.2. BPO in ether is more stable than in methanolto be dissociated to BA. This result comply with (Bollinger and Lewis)[21].

VIII.3. Solution [5] shows zero change ofBA to BPO.(fig- 11) HPLC diagram for solution [5] after 1 month storage.

\section{Chemical exceplanation and test for BPO formation}

IX.1. the chemical exceplanation of BPO formation from BA.A mentioned earlier [22] ethers are normally rather inert they do. However react slowly with oxygen by radical mechanism to form hydro peroxides and peroxides (equation- 3 and 4). These hydro peroxides and ether peroxides react with BA to form BPO. (equation5).

$$
\mathbf{R O C H 3}+\mathbf{O 2} \rightarrow \mathbf{R O C H 2 O O H} \text { (hydroperoxide) --------------Equation } 3
$$

2ROCH2OOH $\rightarrow$ ROCH2OOCH2OR (ether peroxides) --------Equation 4

\section{$\mathbf{2 C 6 H 5 C O 2 H}(\mathrm{BA})+\mathbf{R O C H 2 O O H} \rightarrow[\mathbf{C 6 H 5 C}(\mathrm{O})]$ 2O2(BPO) -Equation 5}

This chemical mechanism is also for alcohol because alcohol is one of peroxide forming compounds [23].

IX.2. Test for peroxide formation ; check for formation of BPO did Iodide test peroxides react with potassium iodide to produce Iodine which make the solution yellow to brown in color. But $5 \mathrm{mls}$ of freshly prepared solution of [ BA in ether] in a test tube add $1 \mathrm{ml}$ of $50 \% \mathrm{KI}$. Let to stand for 15 mints in dark place. repeat the test with old [one month]prepared BA in ether solution. The second one gives yellow color indicates Iodine formation.

\section{$X$. Tables and diagrams}

\begin{tabular}{|l|l|l|l|l|l|}
\hline $\begin{array}{l}\text { Lambda } \\
\text { maximum[nm] }\end{array}$ & $\begin{array}{l}\text { Retention } \\
\text { time }\end{array}$ & $\begin{array}{l}\text { Area under } \\
\text { the curve }\end{array}$ & $\begin{array}{l}\text { Area percent } \\
\%\end{array}$ & $\begin{array}{l}\text { Area unite peak } \\
\text { high }(\mathrm{mAU})\end{array}$ & $\begin{array}{l}\text { Tailing of the } \\
\text { peak minuts }\end{array}$ \\
\hline 230 & 5.71 & $\mathbf{3 8 3 7 7 3 2 1}$ & $\mathbf{8 6 . 8 4}$ & 1250 & $1.4 \pm 4$ \\
\hline 235 & 5.75 & 44536035 & 90.93 & 1250 & $1.4 \pm 4$ \\
\hline 240 & 5.36 & 65645156 & 95.84 & 1500 & $1.2 \pm 4$ \\
\hline 250 & 5.38 & 22845556 & 95.609 & 500 & $1.5 \pm 5$ \\
\hline 260 & 5.355 & 7056155 & 93.086 & 150 & $1.3 \pm 4$ \\
\hline 270 & 4.943 & 658422 & 84.66 & 150 & $1.5+5$ \\
\hline
\end{tabular}

(Table-1) peak resolution of BPO in deferent Lmax HPLC diagrams

\begin{tabular}{|c|c|c|c|c|c|c|c|}
\hline Storage time & 1 hour & 1 day & 1 week & 2 weeks & 1 month & 3 months & 4 months \\
\hline BA & $97 \%$ & $91 \%$ & $86.5 \%$ & $\mathbf{8 3 . 8 \%}$ & $57 \%$ & $34 \%$ & $20 \%$ \\
\hline BPO & $3 \%$ & $9 \%$ & $13.5 \%$ & $16.2 \%$ & $\mathbf{4 3 \%}$ & $\mathbf{6 6 \%}$ & $\mathbf{8 0 \%}$ \\
\hline
\end{tabular}

(Table-2) effects of ether solvent on BA with storage time

\begin{tabular}{|c|c|c|c|c|c|}
\hline Storage time & 1 hour & 1 day & 1 week & 2 weeks & 1 month \\
\hline BA & $99.5 \%$ & $95.5 \%$ & $93 \%$ & $87.5 \%$ & $83 \%$ \\
\hline BpO & $0.5 \%$ & $4.5 \%$ & $7 \%$ & $12.5 \%$ & $17 \%$ \\
\hline
\end{tabular}

(Table-3) Effects of methanol solvent on BAwith storage time

\begin{tabular}{|c|c|c|c|c|c|c|}
\hline Storage time & 1 hour & 1 day & 2 weeks & 1 month & 3 month & 4months \\
\hline BPO & $\mathbf{9 9 \%}$ & $\mathbf{9 4 . 1 \%}$ & $\mathbf{9 2 \%}$ & $\mathbf{9 1 . 5 \%}$ & $\mathbf{9 2 . 3 \%}$ & $\mathbf{9 1 . 5 \%}$ \\
\hline BA & $1 \%$ & $5.9 \%$ & $\mathbf{8 \%}$ & $\mathbf{8 . 5 \%}$ & $\mathbf{7 . 7 \%}$ & $\mathbf{8 . 5 \%}$ \\
\hline
\end{tabular}

(Table-4) stability of BPO inether solvent with its storage time

\begin{tabular}{|c|c|c|c|c|}
\hline Storage time & 1houre & 1 day & 1 week & 1 month \\
\hline BPO \% in Methanol & $\mathbf{9 9 \%}$ & $\mathbf{9 7 \%}$ & $\mathbf{9 0 \%}$ & $\mathbf{8 4 \%}$ \\
\hline BA\% in Methanol & $1 \%$ & $\mathbf{3 \%}$ & $\mathbf{1 0 \%}$ & $16 \%$ \\
\hline
\end{tabular}

(Table-5) storage of BPO in methanol and the percent if its dissociation to BA 

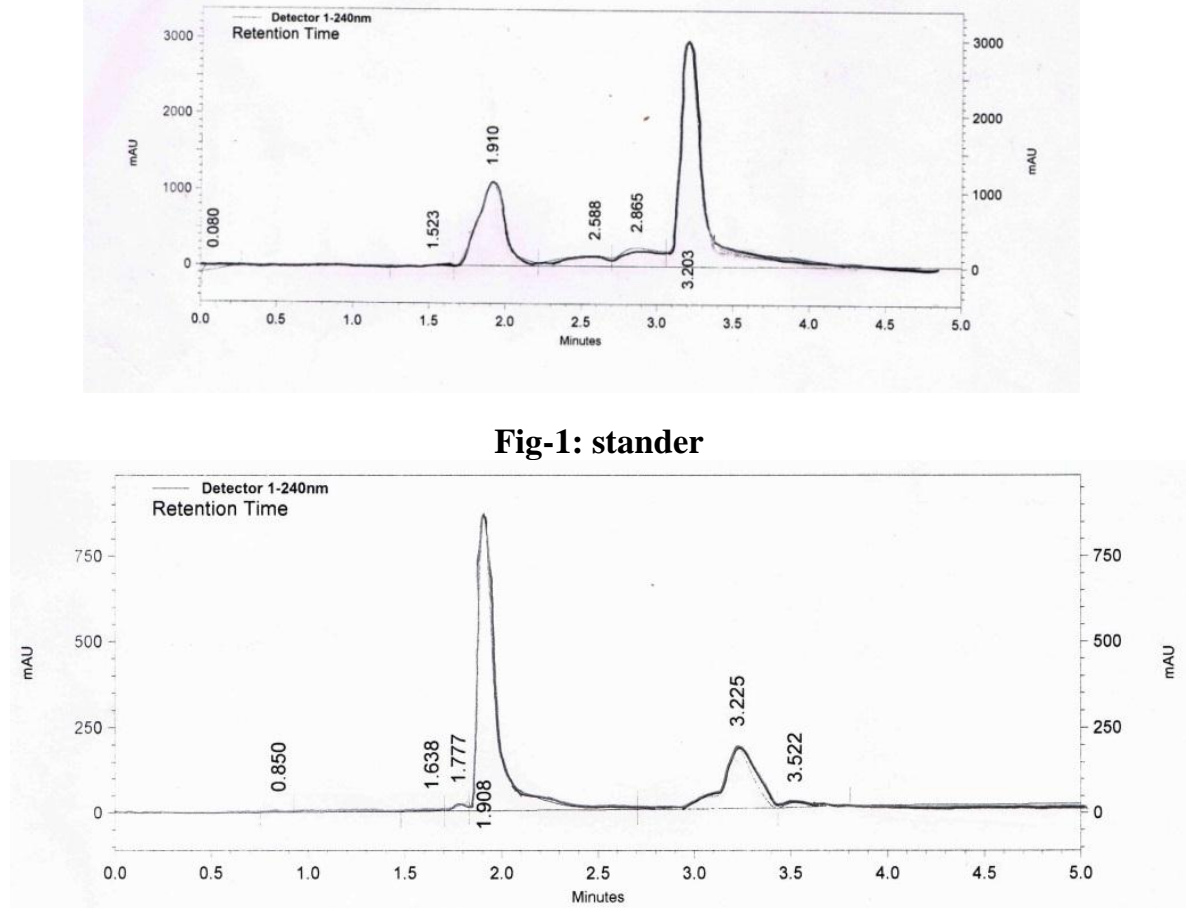

Fig-2:test

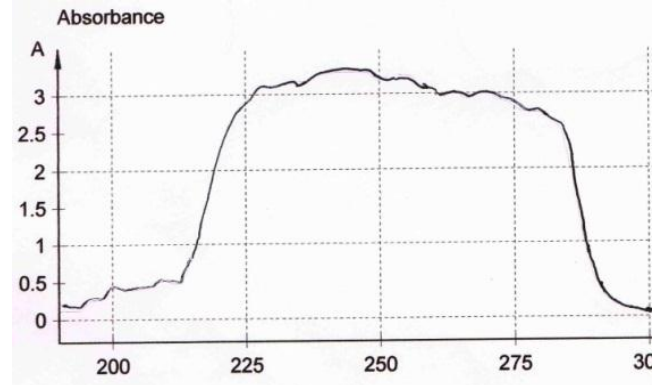

Fig-3: Absorbance diagram for BPO

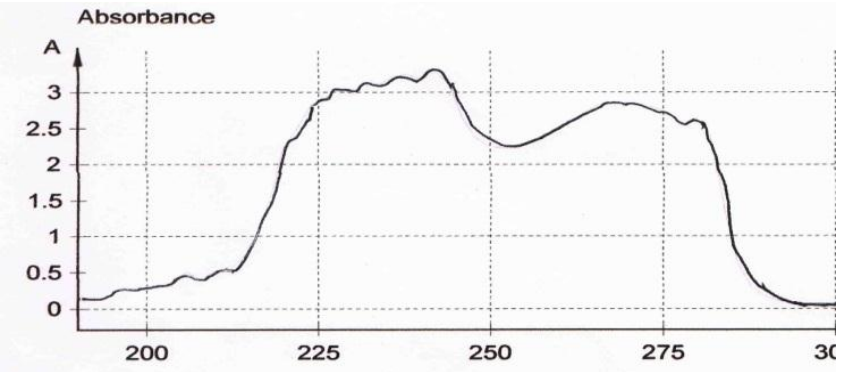

Fig-4:absorbance diagram for BA

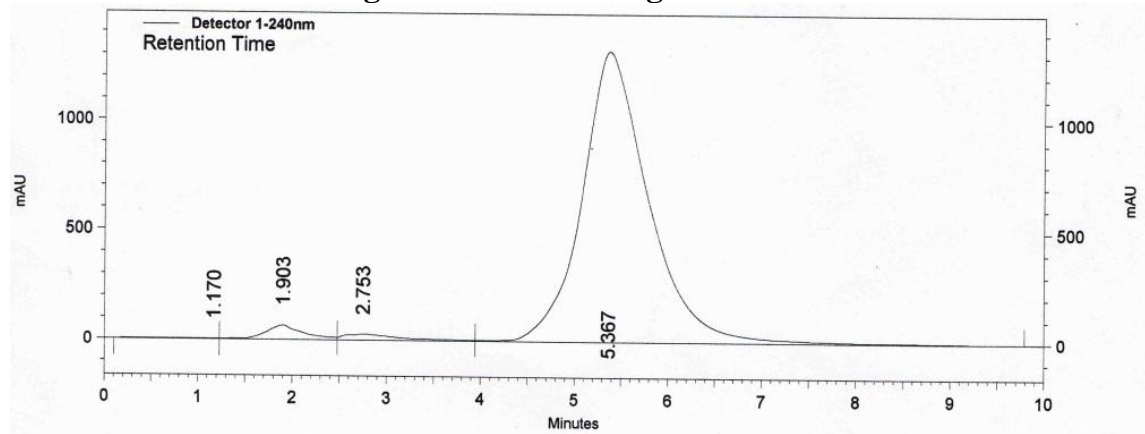

Fig-5:Thehigh resolution of BPO at Lmax 240[nm] 


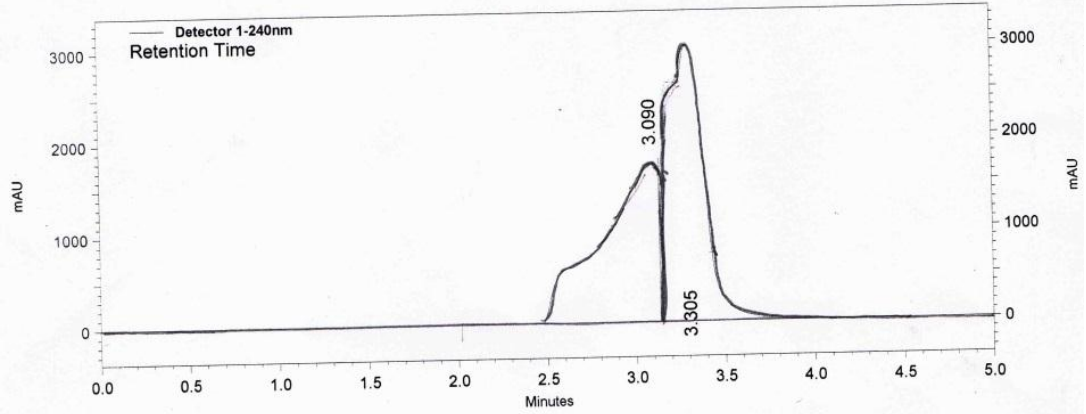

Fig-6:Separation of BPO and BA mixture using normal phase column

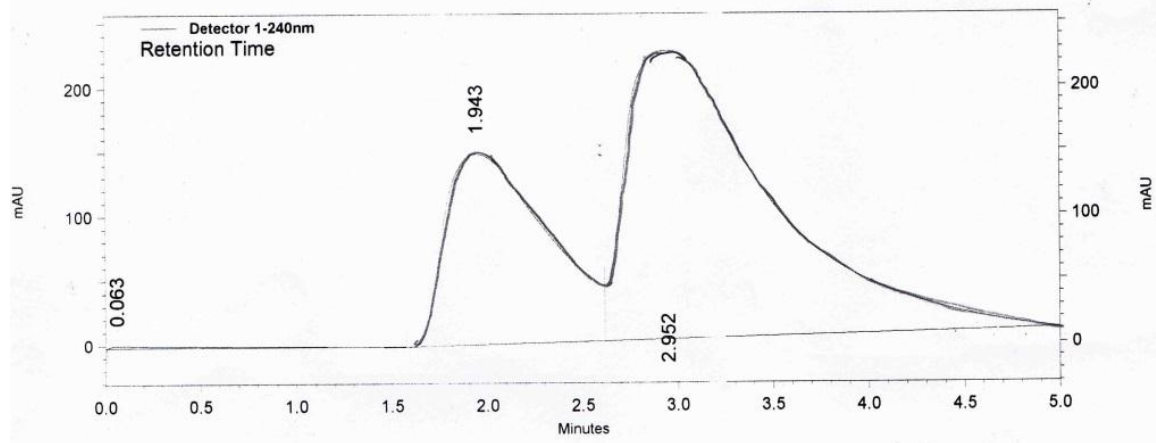

Fig-7: Separationof BPO and BA mixture using ODS reversed phase column

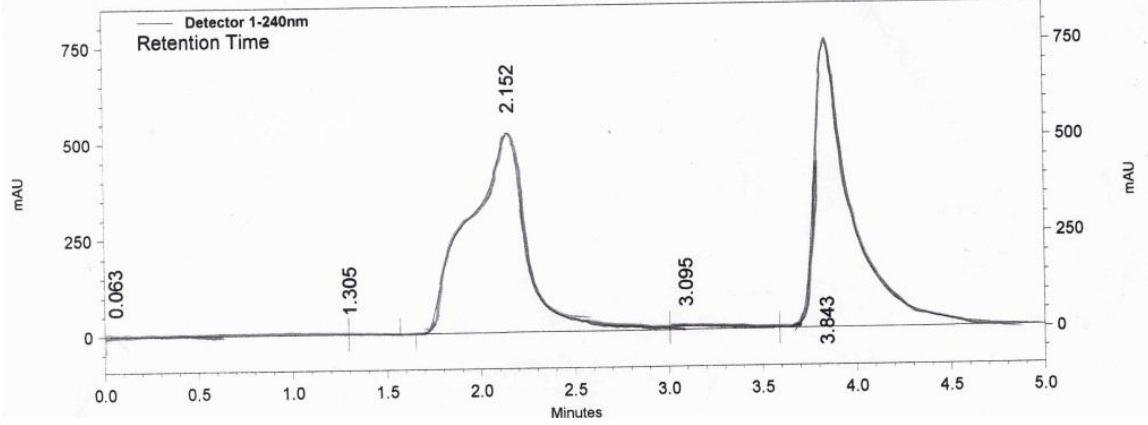

Fig-8: separation of BPO and BA mixture using normal phase column Eurospher-100 C18 Si, 4.6mm ID.

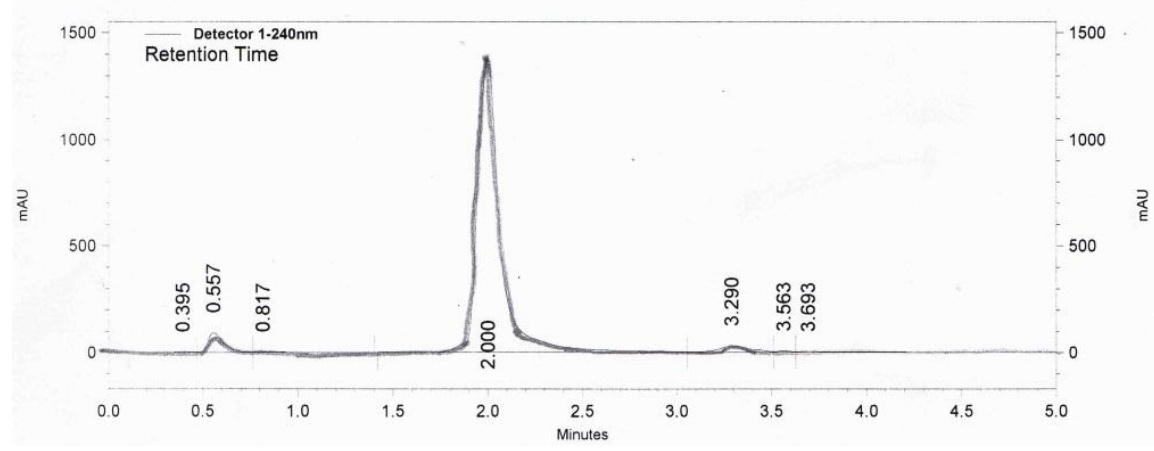

Fig-9:BA in ether solvent after one hour storage. 


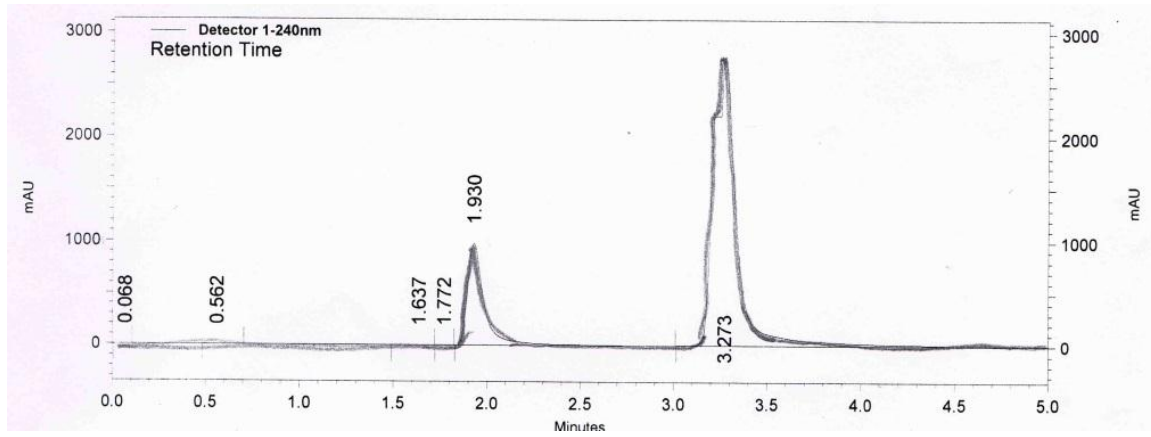

Fig-10:BA in ether solvent after 4 months of storage

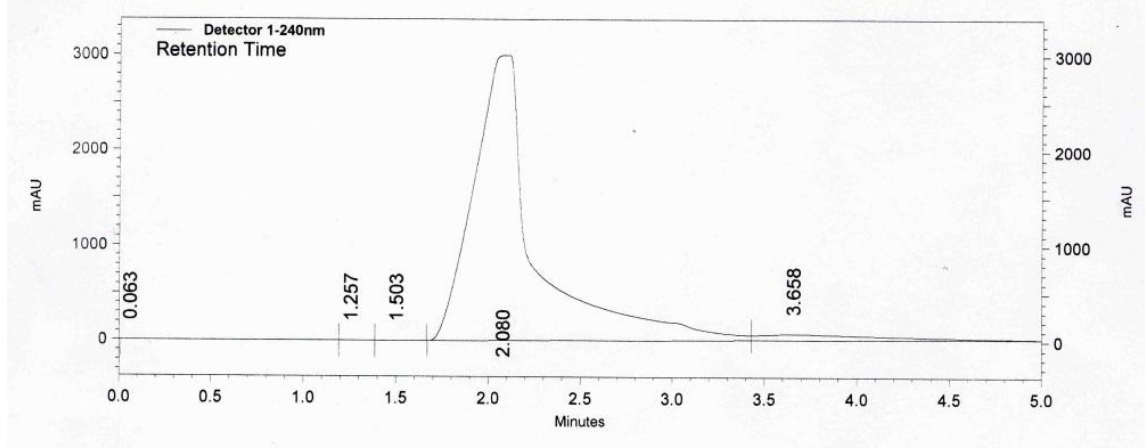

Fig-11:BA in n-Hexane solvent after 1month of storage

\section{Discussion}

X.1. the result we get in assay of the acne lotion by HPLC indicate how much this method is accurate and with low error. To prove that we go back to our result and by simple calculation we see how much the deference is very small between the theoretical and practical result. If our tested material contains exactly $100 \mathrm{mg}$ of BPO and by our HPLC assayBPO was $6 \mathrm{mg}$ practically BA was $95 \mathrm{mg}$ if we calculate the wt. of BA. Theoretically we say the wt of dissociated BPO must be $94 \mathrm{mg}$ but the wt. of BA will be more than $94 \mathrm{mg}$ since one mole of BPO gives two mole of BA and $242 \mathrm{gm}$ of BPO gives us $244 \mathrm{gm}$ of BA. So $94 \mathrm{mg}$ of BPO produced $94.8 \mathrm{mg}$ of BA. So the deference is very low.

X.2. for separation of compounds which non polar or slightly polar we used. Frequently, reversed phase columns packed with a chemically bonded octadecylsilyl coated silica; such columns are referred to as C-18 and are very non-polar.[24] We get better separation when we used the normal phase of column. We noticed that silica normal phase column in our HPLC method when the mobile phase polar we get better resolution and accuracy and separation between BA and BPO. Wither we used high or low concentration of sample.

X.3.this method is also sensitive it gives a good resolution to the tested material concentration from $0.1 \mathrm{mg} / 1 \mathrm{ml}$ to $2.5 \mathrm{mg} / 1 \mathrm{ml}$.

X.4. we must do the assay by HPLC within 12 hoursnot because distraction of BPO to BA but from changing BA to BPO.

X.5.our new method differ from anther HPLC methods by type of the column and it needs very short time it needs only 4 mints low price mobile phase. Easy and clear but it have stability of low time.

X.6.The formation of peroxide in methyl ether and methanol is very rear because the peroxides formed from diethyl ether and higher. And from propel alcohol and higher molecular Wight [23]. To explain this phenomenon, we may say that BA in solvent contains electron rich atom with high electronagativty under goes free radical reaction slowly to form benzoic hydro peroxide. Then slowly react with another BA molecule to form BPO.(equation-6).

$2 \mathrm{C} 6 \mathrm{H} 5 \mathrm{COOH}+\mathrm{O} 2 \rightarrow 2 \mathrm{C} 6 \mathrm{H} 5 \mathrm{COOOH} \rightarrow[\mathrm{C} 6 \mathrm{H} 5 \mathrm{CO}] 2 \mathrm{O} 2+\mathrm{H20}+00-----$ Equation 6(Equation 6 isonly suggestion needs approve I suggest this equation for two responses one because alkane solvent did not form BPO. And two because diethyl ether and methanol did not form peroxides easily).

\section{References}

[1]. B.C.Brodie, (1858), "Ueber die Bildung der HyperoxydeorganischerSäureradicale",JustusLiebigs Ann. Chem.108: 79-83, doi:.\%10.1002/jlac.18581080117

[2]. Li, Hui, III (1998), -2Synthesis, Characterization and Properties of Vinyl Ester Matrix Resins, Ph.D. Dissertation, University of Vermont, Chapter 2

[3]. Benzoyl peroxide, SIDS Initial Assessment Report, Geneva: United Nations Environment Programme, April 2004 
[4]. K.Herbert; G,Peter:H.Siegmeier:, M,Wilfried: "Peroxy Compounds, Organic", Ullmann's Encyclopedia of Industrial Chemistry,(2005)Weinheim: Wiley-VCH, doi:.\%F_10.1002/14356007.a19_199

[5]. Official Methods of Analysis, 10th Ed.(1965). p 199. Association of Official Agricultural Chemists: Washington, D.C.

[6]. Joint FAO/WHO Expert Committee on Food Additives: 'Specifications for the identity and purity of food additives and their toxicological evaluation: emulsifiers, stabilizers, bleaching and maturing agents'. 7th Report(1964), p 155. WHO Techn. Rep. Ser. No. 281. Geneva.

[7]. P. Armandola, Selezione Tec. Molitoria, 14, 111 (1963); cited in Chem. Abstr. 61, 1173 h (1964).

[8]. I. A. Korshunov and A. I. Kalinin, Khim. PerekisnykhSoedin.,Akad. Nauk SSSR, Inst. Obshch. i. Neorgan. Khim. 279 (1963); cited in Chem. Abstr. 60, 15149 e (1964).

[9]. A. Barderet. M. Brerdee and G. Reiss(1965). Bull. Soc. Chim. France, 3, 626-8

[10]. H. M. Pylypiw, M. T. Journal of chromatography A2000; 883, 1-2, pp. 299-304.

[11]. D.Shan, Q.Fang, D.Zhue, H.Xue. Inhibitive detectionof benzoic acid using a novel phenol biosensor basedonpolyanilinepolyacrylonitrile composite matrix. Talanta 2007; 72, pp.1267-1272.

[12]. Coverly J, Peters L, Whittle E, BasketterDA.Susceptibility to skin stinging, non-immunologiccontacturticaria and acute skin irritation; is there arelationship? Contact dermatitis, 1998; 38(2) pp.90-95.

[13]. JC.Castro, MA.Delgado, MJ.Sánchez. Simultaneous 2nd order derivativespectrophotometric determination of sorbic and benzoic acids in soft drinks. Analytical letters,( 1992);25(12), pp.2357-2376.

[14]. B.Larsson. Gas-liquid chromatographicdetermination of benzoic acid and sorbic acid infoods: MNKL collaborative study. Journal of the Association of Official Analytical Chemists,( 1983);66, pp.775-780

[15]. M.Arens, C.Gertz. BestimmungderKonservierungsstoffe - GemeinsschaftsarbeitderDGF, 110. Mitteilung: Deutsche EinheitsmethodenzurUntersuchung von Fetten, Fettprodukten,Tensiden und verwandtenStoffen, 83.ü Mitt.:Analyse von fettreichenLebensmitteln IV. Fatscience and technology, (1990); 92(3), pp.107-109

[16]. Yu Huang; Xia Zhang. Determination of benzoic acid and sorbic acid in sauce by HPLC-MS Pharmacy Coll., Ningxia Med. Univ., Yinchuan, China; Page(s):2086 - 2088 Print ISBN:978-1-4244-9172-8 .

[17]. Z.Pan, L.Wang, MO.Weimin, Determination of benzoic acid in soft drinks by gas chromatography with on-line pyrolytic methylation technique AnalyticaChimicaActa 01/2005; DOI:10.1016/j.aca.2005.04.072

[18]. Wei.HUANG ;Simultaneous Determination of Benzoylperoxide and Benzoic Acid Content in Flour by ultraviolet SpectrophotometryLINJianyuan,(College of Biomedical and Environmental Science,ZhejiangWanliUniversity,Zhejiang Ningbo,315100,China) C2006 Tsinghua Tongfang Knowledge Network Technology Co., Ltd.(Beijing)(TTKN),

[19]. MS.Ali., S.Rafiuddin S, MI.Munir, An isocratic reversed-phase high-performance liquid chromatographic method for the simultaneous determination of benzoyl peroxide and the related compounds benzoic acid, benzaldehyde, ethyl benzoate, methylparaben, and propylparaben in dermal preparations. J AOAC Int.(2008) Sep-Oct;91(5):1025-36

[20]. USP28-NF23Page 237Pharmacopeial Forum:Volume No.30(2)Page 456

[21]. Bollinger JN, Lewis D, Mendez VM.Benzoyl peroxide stability in pharmaceutical gel preparations.J Pharm Sci.(1977) May;66(5):718-22.

[22]. P,Volhardt. N, Schore."Organic chemistry structure and function"6th ed(2009).P357.W.H.Freeman and com. New Yurok.

[23]. D.E Clark," Peroxides and peroxide forming compounds" .Chem. Health Saf.(2001),8(5).12-21.

[24]. D.C. Harris, "Quantitative Chemical Analysis; 5th Edition(1999)"; W.H. Freeman .Company: New York. 